\title{
Evidence-Based of Nonoperative Treatment in Adolescent Idiopathic Scoliosis
}

\author{
Safak Ekinci ${ }^{1}$, Faruk Akyildiz ${ }^{2}$, Kenan Koca ${ }^{3}$, Omer Ersen ${ }^{4}$, Sebahattin Sari ${ }^{5}$ \\ ${ }^{1}$ Department of Orthopaedic Surgery, Agri Military Hospital, Agri, Turkey \\ ${ }^{2}$ Department of Orthopaedic Surgery, Malatya Military Hospital, Malatya, Turkey \\ ${ }^{3}$ Department of Orthopaedic Surgery, Gulhane Military Hospital, Ankara, Turkey \\ ${ }^{4}$ Department of Orthopaedic Surgery, Erzurum Military Hospital, Erzurum, Turkey \\ ${ }^{5}$ Department of Radiology, Gulhane Military Hospital, Ankara, Turkey
}

Dear Editor,

We would like to discuss the publication entitled "Evidence-based of nonoperative treatment in adolescent idiopathic scoliosis [1]" which we read with great interest. In his study, the author reviewed articles concerning adolescent idiopathic scoliosis (AIS). Honestly the objective of the study is noteworthy and we have some questions for author:

(1) Scoliosis of less than $20^{\circ}$ should be followed up in periodic outpatient visits at 4 to 6 month intervals, and new X-rays should be taken if progression is suspected [2]. Bracing is generally recommended for scoliosis between $30^{\circ}$ and $45^{\circ}$ before the termination of bone growth. Bracing has been shown to successfully prevent curve progression in $75 \%$ in this patient population [3]. The recommendations for the bracing study inclusion were based on patients aged 10 years and above, a Risser sign of 0 to 2 , initial curve magnitude of $25^{\circ}$ to $40^{\circ}$ [4]. What is the authors' opinion on a correlation between scoliosis angle and the Risser sign at therapy planning with AIS patients?

(2) What is the authors' opinion on Charleston and
Providence braces? Have part-time or nighttime bracing any advantages with patient compliance?

(3) Classification of idiopathic scoliosis is of utmost importance in defining curvature by physicians, physiotherapists and orthotic technicians and designing the treatment plan $[5,6]$. Which classification system (King, Peking Union Medical College-PUMC, Lenke) did the author use for providing guidance for patients with AIS?

We appreciate the authors' comments on these concerns.

\section{Conflict of Interest}

No potential conflict of interest relevant to this article was reported.

\section{References}

1. Kim HS. Evidence-based of nonoperative treatment in adolescent idiopathic scoliosis. Asian Spine J 2014;8:695-702.

2. Trobisch P, Suess O, Schwab F. Idiopathic scoliosis. Dtsch Arztebl Int 2010;107:875-83.

Received Dec 12, 2014; Accepted Dec 12, 2014

Corresponding author: Safak Ekinci

Department of Orthopaedic Surgery, Agri Military Hospital, 04000 Erzurum Caddesi, Agri, Turkey

Tel: +90-532-733-9850, Fax: +90-472-215-2747, E-mail: safakekinci@yahoo.com 
3. Rowe DE, Bernstein SM, Riddick MF, Adler F, Emans JB, Gardner-Bonneau D. A meta-analysis of the efficacy of non-operative treatments for idiopathic scoliosis. J Bone Joint Surg Am 1997;79:664-74.

4. Schiller JR, Thakur NA, Eberson CP. Brace management in adolescent idiopathic scoliosis. Clin Orthop
Relat Res 2010;468:670-8.

5. Oguz E, Ekinci S, Ersen O. Review of radiological assessment and classification systems of adolescent idiopathic scoliosis. Totbid Dergisi 2013;12:73-82.

6. Ekinci S, Ersen O. Adolescent idiopathic scoliosis. Arch Clin Exp Surg 2014;3:174-82. 